\title{
Nonverbal Presentation in a Mediation Session
}

\section{Kate Ellis}

Alternative Dispute Resolution has become a popular method for settling grievances. This popularity leads to a likely chance that a mediator will facilitate a crosscultural mediation. With the global boom in cultural interaction-stemming from increased commerce, tourism, and social media-awareness of cultural differences and similarities in nonverbal communication is imperative to respectful engagements and relationships. That said, a mediator's nonverbal presentation is likely to affect the parties' perception of the mediation process. Many nonverbal behaviors, shaped by cultural practices, emerge in hand gestures, facial expressions, eye contact, body language, and posture. This study investigates a mediator's nonverbal communication in terms of hand gestures and eye contact as they relate to the participants' nonverbal preferences in a mediation session. The results of the study demonstrate that Interdependence and Gender Equality (Personal Cultural Orientations) significantly predict participant preference for high nonverbal communication in a mediation context. Discussion relates to Hofstede's Cultural Dimensions and expands our understanding of nonverbal communication. More specifically, and with reference to hand gestures and eye contact, the current study explores the relationship between nonverbal communication and culture within a mediation session, and with attention to the ways in which various ethnicities, races, and persons of varied nationality perceive a Caucasian woman's display of "nonverbals." Such emphases stand to contribute to our understanding of the impact a mediator's hand gestures and contact have on the way that we might predict nonverbal preferences

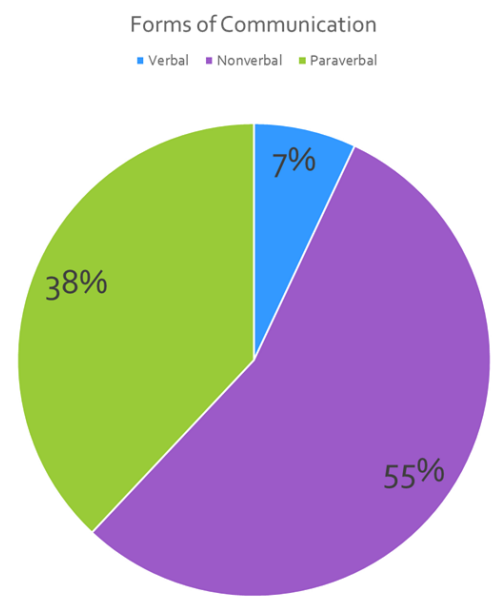

via a Personal Cultural Orientations scale.

As for the importance of nonverbal communication, that has the potential to be significantly more revealing than verbal communication in terms of genuine thoughts and feelings. Indeed, studies have shown that up to $93 \%$ of all communication takes place at a nonverbal and paraverbal level, and the verbal message is better perceived when the nonverbal language further emphasizes it. Additionally, when there is a conflict between what is said and how it is said, people usually believe what they see and not what they hear (even if they do so at a subconscious level) (Topan, 2011). Increasing nonverbal intelligence overall is thus key to effective communication across cultures, as well as in a cross-cultural mediation session. The goal of this project is to draw on the relationship between nonverbal preferences in a mediation session and participants' personal cultural values.

To examine the important intersection of mediation and cultural differences in 
nonverbal communication, we should remind ourselves of such variables as mediation, culture, Hofstede's cultural dimensions, and nonverbal communication. As for mediation, the use of Alternative Dispute Resolution has become a favored method in settling various disputes. This includes the use of arbitration, negotiation, and mediation, whereas mediation can be understood as a process in which an impartial third party facilitates a negotiation between parties in a conflict (Beer \& Packard, 2012). Due to the importance of cultural context, a mediator's nonverbals may have the potential to make or break a mediation session. In a matter of moments, because of the nonverbals of the mediator, parties are likely to get an idea of their level of control in the mediation process. When they perceive the mediator to be engaged - often exhibited through the mediator's heavy eye contact and hand gestures - they may be more open to participate and realize that the mediator is there to help them work through their dispute. When a mediator is closed off and does not appear to be in the moment with the parties, because of lack of eye contact or closed off body posture, they may reflect the mediator's actions and therefore become closed off themselves.

This may be the case for one person and completely different for another, $\mathrm{n}$ which preference is likely based in customary cultural values. Beer \& Packard (2012) express the importance of keeping in mind the ethnicity, race, gender, and nationality of the mediator. Moreover, if the mediator comes from a majority culture and the parties come from a minority culture, that dissonance can create a prejudice before nonverbals are even displayed. This goes to show the importance of familiarizing oneself with expectations for nonverbalcommunication preferences while simultaneously being adaptable to those expectations. Even when mediators familiarize themselves with expectations for nonverbal communication preferences, such expectations may turn out to be inaccurate, in part or in whole. Perhaps, then, the three most effective tools for mediating cross-cultural disputes are the pre-mediation meetings (joint or private), caucuses during mediation, and the Socratic method of questioning (Barkai, 2008).

Moreover, the pre-mediation meetings are important because they constitute the start for the mediator and parties to build rapport. The meeting can be a joint meeting between the mediator and all the parties to the dispute, or a private, ex parte meeting between the mediator and one party (Barkai, 2008). A mediator might hold a less formal, non-substantive, "get-acquainted" meeting with the parties or advocates (or both) before the mediation begins (Abramson, 2004). The pre-mediation meeting is the time in which the parties confirm their understanding of the shared goal for the mediation, their roles as participants in the mediation, and the scope of the mediation. This is also when the mediator reviews their role as the mediator, including what it means to be "impartial" and "neutral." This meeting is also crucial with respect to dialogue about the conditions for the mediation session. To elaborate, the mediator will discuss how and when the parties, as well as the mediator, can withdraw from the process. The mediator also reviews what topics will or will not be discussed (Beer \& Packard, 2012).

The mediation caucus, very useful for cross-cultural outreach, can be understood as a private meeting between the mediator and one of the parties to a dispute (Barkai, 2008). The caucus is a common mediation practice that allows private, ex parte communication between a party and a mediator. The caucus can serve as beneficial for the mediator and the parties since the mediator can get a sense 
of the cultural characteristics of the parties and thereby assess the cultural awareness of each party about the other party's culture. The caucus also gauges knowledge of the culture and values of the opposing party, while allowing the mediator to serve as an interpreter, coach, and teacher, thereby allowing parties to re-establish or create social relationships that are beneficial for resolving conflict (Barkai, 2008).

As Barkai (2008) explained, the Socratic method of questioning in the mediation session can be beneficial, especially when one of the parties is not aware or does not understand the importance of cultural values and differences. A Socratic-method approach in which the mediator asks questions and the parties respond can be very effective in helping the mediator become familiar with the parties and in gauging appropriate and inappropriate nonverbals to display. Regarding optimal outcomes, Beer \& Packard (2012) note that it may be beneficial if the parties in mediation realize that they have a common identity. Identity is often a hot issue in mediation in that it shapes how people present themselves, how they want to be seen and treated, who they "belong" to, and fundamentally how they think of themselves. When the mediator helps the parties realize they likely have more in common than not, this can motivate them to put their differences aside and see each other as human beings that are worthy of accommodation (Beer \& Packard, 2012).

Numerous other factors play into interpreting the meaning behind nonverbal communication, the largest being culture (Topan, 2011). Indeed, one commentator stresses the importance of cultural context in mediation since behaviors lack full meaning in isolation from cultural context (Pedersen, 2006). However, there are many definitions for "culture," and unfortunately, it is common for us to interpret the behaviors of people from other cultures, sometimes leading people to be self-referential in the attribution of significance to non-verbal communication (Barkai, 2008). The current study adopts the definition of "culture" as a "shared system of socially transmitted behavior that describes, defines, and guides people's ways of life, communicated from one generation to the next" (Matsumoto, 2006, p. 220).

Culture is mainly an unspoken, nonverbal phenomenon because most aspects of one's culture are learned through observation and imitation rather than by explicit verbal instruction or expression (Andersen, 1997). The meanings behind nonverbal communication, however, can differ from culture to culture, and vary in degree of comfort and overall preference among varied cultures. Recently, there has been more exposure to these differing nonverbals with increased tourism, elevated usage of social media, and growing recourse to Alternative Dispute Resolution practices to settle disputes. Increased exposure is important in decreasing cross-cultural communication ignorance; more vital, still, is the need to learn why cultures behave the way they do as to try to understand the reasons behind their nonverbals. Here, too, we need recall that a single display of a nonverbal may not have any relevance in isolation from cultural context.

Perhaps the most important factors pertaining to mediation-session nonverbal preferences are high-context versus lowcontext cultural values. By this, I am referring to how people communicate and interact with other people in their culture. A low-context culture consists of people who communicate explicitly and with heavy reliance on verbal communication, whereas those of a high-context culture communicate indirectly and with more reliance on nonverbal communication (Hall, 1977). 
Those in a low-context culture communicate directly even when the topic may be sensitive. In contrast, those in a high-context culture may avoid discussions of sensitive matters. Also, high-context cultures tend to value tradition, whereas low-context cultures tend to value change and are more futureoriented (see Table 1). Most observers would say that people in the United States, Canada, Australia, New Zealand and most Northern and Western European countries use direct, explicit, low-context communication, and that Asian countries, along with most of the rest of the world, use indirect, implicit, highcontext communication (Barkai, 2008).

\section{Table 1. Hall's Low-Context versus High-Context}

\begin{tabular}{cc}
\hline Low-Context & High-Context \\
\hline Overt Language & Covert Language \\
Details Verbalized & Reliance on Nonverbals over Verbals \\
Future-Oriented & Value Tradition \\
Task-Oriented & Relationship-Oriented \\
Individualistic & Team-Oriented \\
\hline
\end{tabular}

Six cultural dimensions are introduced from Hofstede's (1980, 2001) studies with the purpose of categorizing cultural preferences and reasons why people behave the way they do. Among those reasons are power distance, femininity versus masculinity, collectivism versus individualism, uncertainty avoidance, shortterm versus long-term orientation, and restraint versus indulgence. It is also important to keep in mind the context, clusters, congruence, consistency, and culture when analyzing preferences. That is necessary because, while persons may "read" body language, they should also understand how to delve into the meaning behind the various signals (Topan, 2011).
Context refers to the circumstances in which the interaction takes place. Clusters of nonverbal cues should also be taken into consideration when a person analyzes body language, for a single gesture can imply a host of meanings. As it pertains to context, congruence refers to the coordination between the verbal message and the nonverbal language, while consistency refers to the relationship between the baseline behavior of a person and the changes that behavior suffers when the person is under stress. Finally, as briefly stated before, culture and cultural heritage have a great influence on all nonverbal communication (Goman, 2008). All in all, culture shapes display rules - that is, of to whom, on what occasions, and why certain nonverbal 
expressions should be revealed, or else suppressed (Ekman \& Friesen, 1975; Ekman \& Oster, 1979). Indeed, societal cultures harbor values that unconsciously and implicitly engender tendencies to prefer certain states of affairs over others (Hofstede, 2001). On the other hand, organizational cultures inhabit more visible and conscious practices in the way that people perceive what goes on in their organizational environment. The idea of separating cultures into distinct dimensions was first expressed in a 1962 study in which U.S anthropologist Clyde Kluckhohn argued that there should be universal categories of culture; later scholars theorized about the nature of problems within a society that humans face on a day-to-day basis and how these can be categorized, defined, and studied (Hofstede, 2001).

Hofstede's cultural dimensions date back to his original seminal work, Cultural Consequences: International Differences in Work-Related Values, in which he discusses the results for his original study. His fourdimension framework began with power distance, individualism versus collectivism, masculinity versus femininity, as well as uncertainty avoidance (Hofstede, 1980). When Hofstede's Cultural Consequences first appeared in 1980, it represented a new paradigm in social science research. Moreover, this piece analyzed survey-based values data at the national level while quantifying differences among national cultures in accord with their positions on these dimensions (Hofstede, 2011). To this day, Hofstede's cultural dimensions are beneficial for their ability to conceptualize values across and within cultures. Moreover, Hofstede's cultural values are endorsed by Clark (1990), since there are many similarities among the different typologies of culture, and because their dimensions are well captured in Hofstede's typology. Soares, Farhangmehr, \& Shoham (2007) also endorsed the relevance of the Hofstede cultural dimensions to international business and consumer behavior through a comprehensive review of related literature (Yoo et al, 2011). For all that, however,

Hofstede's theories faced criticism early on, and by the 1990s the paradigm had been taken over by many others as discussions of the content and number of dimensions were of common interest. As a result, what was once a four-dimension framework developed into what are now six dimensions.

As previously stated, these preferences within a society are organized into dimensions of power distance, femininity versus masculinity, collectivism versus individualism, uncertainty avoidance, short-term versus long-term orientation, and restraint versus indulgence. Each country has been positioned relative to other countries through a score on each dimension. The dimensions are statistically distinct and do occur in all possible combinations, although some combinations are more frequent than others.

Hofstede's cultural dimension of power distance delves into the idea that those with less power in a society expect and accept an unequal distribution of social power (Hofstede, 2011). Moreover, the idea of power distance suggests that a society's level of inequality is endorsed by the followers as much as it is by the leaders or those with higher power. Power and inequality are extremely fundamental facts of any society in that all societies are unequal, but some are more unequal than others (Hofstede, 2011). In Hofstede's 2010 study, power-distance index scores are listed for 76 countries as they tend to be higher for East European, Latin, Asian and African countries and lower for Germanic and English-speaking Western countries.

Hofstede's femininity versus masculinity cultural dimension refers to the 
division of emotional roles between women and men in a shared society. Moreover, cultures that are of a masculine nature tend to see a man's display of emotions as frowned upon, while cultures that are more feminine in nature see displays of emotion as more acceptable. Also, the women in feminine countries have the same modest, caring values as the men, whereas in the masculine countries they are somewhat assertive and competitive, but not as much as the men. These countries show a gap between men's values and women's values (Hofstede et al, 1998). Research has shown that masculinity is high in Japan, German speaking countries, and in some Latin countries like Italy and Mexico. It is moderately high in Englishspeaking Western countries and low in Nordic countries and the Netherlands. It is seen to be moderately low in some Latin and Asian countries like France, Spain, Portugal, Chile, Korea, and Thailand (Hofstede, 2009).

Hofstede's collectivistic versus individualistic cultural dimension seeks to gauge one's values regarding the importance of self-reliance versus focusing on the values of a group. One who comes from an individualistic society is expected to look after themselves and their immediate family, while one from a collectivistic society is expected to integrate and remain loyal to strong, cohesive groups, usually extended family starting at birth (Hofstede, 2011). Research has shown that individualism prevails in developed and Western countries, while collectivism prevails in less developed and Eastern countries. Japan tends to take a centralized position on this dimension (Hofstede, 2009). Individualistic characteristics are typically representative of low-context cultures whereas collectivistic characteristics are representative of a highcontext culture (Barkai, 2008).

Hofstede's uncertainty avoidance refers to the level of stress in a society in the face of an unknown future. This dimension delves into the extent in which a culture programs its members to feel either uncomfortable or comfortable in unstructured situations. Unstructured situations are novel, unknown, surprising, and unusual. Uncertainty avoidance cultures try to minimize the possibility of such situations by strict behavioral codes, laws and rules, disapproval of deviant opinions, and a belief in absolute Truth - that is, "there can only be one Truth and we have it." Research has shown that people in uncertaintyavoidance countries are also more emotional and motivated by inner nervous energy. On the other end of the spectrum, uncertaintyaccepting cultures are more tolerant of opinions differing from the norm. They also try to have fewer rules, and on the philosophical and religious level they are empiricist, relativist, and allow different currents to flow side by side (Hofstede, 2011). This dimension can also be understood as free-thinking (low uncertainty avoidance) versus conformist (high uncertainty avoidance). Uncertainty avoidance scores are seen to be higher in East and Central European countries, in Latin countries, in Japan and in German-speaking countries, while being lower in English speaking, Nordic, and Chinese cultures (Hofstede, 2009).

Hofstede's short-term versus longterm orientation refers to the choice of focus for people's efforts, whether it be the future (long-term) or the present and past (shortterm). Moreover, one who comes from a short-term society may focus on the here and now, whereas persons in long-term societies may focus on future effects and consequences when making decisions. This dimension characterized a study among students in twenty-three countries. Results were developed from a questionnaire designed by Chinese scholars (Hofstede \& Bond, 1988). Research shows that East Asian 
countries - specifically in China, Hong Kong, Taiwan, Japan, and South Korea - are more long-term oriented. To a lesser extent, India and Brazil are also seen to be long-term oriented. Most European countries fall in the middle of the spectrum. The United States, Britain, Africa, and a few Islamic countries appear to have short-term orientation (Hofstede, 2009).

The last of the cultural dimensions, restraint versus indulgence, describes the gratification versus control of basic human desires related to enjoying life. A society that values indulgence can be understood as a society that allows relatively free gratification of basic and natural human desires related to enjoying life and having fun. On the other hand, a culture that values restraint can be understood as a society that controls gratification of needs and regulates it by means of strict social norms (Hofstede, 2011). Indulgence tends to exist in South and North America, in Western Europe, and in parts of Sub-Saharan Africa, while restraint is more prevalent in Eastern Europe, Asia and across the Muslim culture. Mediterranean Europe takes a more balanced position of indulgence and restraint.

Communication involves a socially shared symbol system, or code (Weiner et al, 1972). Nonverbal communication, specifically, can be understood as any communicative act that does not use speech. This includes but is not limited to, body posture, physical appearance, gaze, proxemics, and the use of artifacts (Duncan, 1969). Nonverbal communication appears across all cultures and is more prevalent in some than in others. The quality, quantity, and type of nonverbals may ultimately depend on one's personality; however, those nonverbals remain highly influenced by what is taught or shown, whether that be explicit or implicit (Mandal, 2014). We are also constantly learning proper communication through trial and error. Nonverbals that are acceptable in one setting may not be appropriate in another. This depiction of what is considered acceptable is oftentimes based on the setting and context of a situation.

Numerous studies have further explained the importance of nonverbal communication within and across cultures. Poyotos (1977) classified nonverbal phenomena based on the sensory channels, possible combinations of verbal and nonverbal communications, and the interaction potential of the behavior. These sensory channels are acoustic, visual, olfactory, and tactile. The classes identified are the verbal-vocal, nonverbal-vocal, as well as nonverbal-nonvocal. Theories introduced by Hall have shown that, although humans are culture-producing animals, in the remote past there were no humans and no culture. This infra-culture has evolved into what is now considered culture. Hall's major investigations feature the use of space (Mandal, 2014). To elaborate, every living thing has a physical space that separates it from the outside environment. It is with respect to this idea that we understand the importance of what our proxemics communicate to the society in which we inhabit (Hall, 1977), and better comprehend what others proxemics communicate to us. As humans, we tend to carry around an invisible bubble that we call our personal space. Whether we keep it in constant check or acknowledge it only when violated, "We may be more territorial about our personal space than we are about any other single area" (Remland, p. 119, 2017).

Such observations shed light, as well, on hand gestures. A review of the varied types of nonverbals calls on us to realize that context is relevant in any given situation, as such context pertains to intercultural nonverbal communication. A hand gesture, for example, can have many meanings, 
depending on the cultural context (Topan, 2011). An example of the importance of context was displayed when President Bush greeted a large crowd of Australians with a gesture, he assumed was Churchill's famous "V" (for victory) gesture. President Bush unfortunately had the gesture backwards, which resulted in his flashing the large crowd of the British Commonwealth with the equivalent of the American middle finger (Archer, 1997). This example goes to show that even when an obscene gesture occurs unintentionally, it can connote either offense or ignorance.

There are various types of gestures across cultures. These gestures include emblematic gestures, which take the place of spoken words, deictic gestures to point at or refer to things, and pantomimic gestures to act things out. We also use iconic gestures to visualize concrete referents, metaphoric gestures to visualize abstract referents, and batonic gestures to highlight important points. While all these gestures may be relevant to the cultural context in which they are performed, emblematic gestures are perhaps the most relevant to their cultural context and setting. Indeed, when visiting a different culture, one may find that a certain hand gesture entails a meaning that runs opposite to that of our preconception; hence, the need for guidance when interpreting a gesture by someone in their own cultural ingroup (Marsh, Elfenbein \& Ambady, 2003).

Even when we think we recognize a gesture while abroad, we may not recognize it as well as we think. In some cases, the confusion can be costly. Moreover, when an identical hand movement occurs in two cultures, the emblematic meaning may vary significantly. For example, the waving gesture for "good-bye" in the United States means "come here" in Japan. A thumbs up for "good luck" in the United States means "screw you" in Iran, and boyfriend in Japan.
Finally, the gesture for "OK" in the United States means "sex" in Mexico (Andersen, 1997). These are only a few ways in which understanding the context is crucial for displaying the intended gesture, and for refraining from offensive behavior.

Increasing cultural nonverbal intelligence regarding hand gestures has become imperative. This is potentially due to previous failures to accurately read hand gestures. In a respectful relationship, knowing or trying to understand how other cultures communicate is key building respectful relationships. Cultural context when displaying hand gestures is important in a mediation session. Someone from one culture may see a display of heavy hand gestures as engaging and inviting. In contrast, one from another culture may find the same gestures as intimidating and overwhelming. Similarly, subject to scrutiny are facial expressions and their universality, as noted by contemporary scholar Charles Darwin, in The Expression of Emotion in Man and Animals. He there suggests that emotions and their expressions, having evolved across species, were evolutionarily adaptive, biologically innate, and universal across all human and even nonhuman primates. According to Darwin (1972/1998), humans, regardless of race or culture, possess the ability to express emotions in the same ways, primarily through their faces (Matsumoto, 2006). Researchers Sylvan Tomkins and Paul Ekman obtained judgments of faces thought to express emotions pan culturally and demonstrated that all cultures agreed on the emotions portrayed in the expressions, providing the first evidence for their universality (Ekman, 1972). These findings demonstrated the existence of six universal expressions, those being anger, disgust, fear, happiness, sadness, and surprise. While new findings support the view that there are universal facial expressions of emotion, one possible limit on these findings is that all of 
the observers were college students who have been exposed to a degree of similar massmedia depictions of facial expressions (Ekman, 1972).

In one type of investigation, members of one culture were asked to show how their face would look if they were the person in each of a number of different emotional contexts (e.g., "you feel sad because your child died," "you are angry and about to fight"). Universality of expressions was demonstrated when observers in another culture succeeded in identifying which emotional contexts the expressions were intended to portray.

This finding had unusual importance because the people displaying the expressions were members of the isolated New Guinea culture. The ability of Americans to understand these New Guinean expressions could not be attributed to prior contact between these groups or to both having learned their expressions from mass media models (Ekman \& Friesen, 1971). There are a few issues with these findings, however. First, there has only been one such study. It has not been repeated in another preliterate, visually isolated culture, nor for that matter in a literate, non-Western or Western culture. Second, not all six emotions portrayed were accurately recognized. Anger, disgust, happiness, and sadness were distinguished from each other and from fear and surprise, but the American observers could not distinguish the New Guineans portrayals of fear and surprise. Third, the facial expressions were posed (Ekman, 1972).

Eye contact, or lack thereof, is another form of nonverbal communication across cultures that carries a variety of meanings. For example, gaze is used in all cultures, but the amount of gaze differs quite largely. Research on humans and nonhuman primates has shown that gaze is associated with dominance, power, or aggression (Fehr \& Exline, 1987) as well as affiliation and nurturance (Argyle \& Cook, 1976). Fehr and Exline suggested that the affiliative aspects of gazing begin in infancy, as infants attend to adults as their source of care and protection (Matsumoto, 2006).

A study occurred in which a pair of students from different countries had their amount of gaze observed. Arabs and Latin Americans showed the highest levels of gaze while Indians and northern Europeans showed the lowest levels. When people from different cultures were brought together to conduct this study, those with low levels of gaze were seen as impolite, dishonest, or not paying attention, while those with high levels of gaze were seen as threatening or insulting. Some cultures may implicitly or explicitly have certain rules about gaze. For example, there may be a rule about not looking at specific body parts, or specific people (Argyle \& Cook, 1976). In Australia, if little to no eye contact is made, it is assumed that the person is shy, uninterested, or untrustworthy. If eye contact is too prolonged, it is interpreted as very high interest, and between males and females, as sexual interest (Barna, 1997).

Regarding such tendencies, we would do well to recall studies that address differences in cultural values (Hofstede, 1980; Sharma, 2009), relative to the interpretation and communication of messages. Recognizing and adapting to the differences of nonverbal communication across cultures is important (Barkai, 2008) in understanding the impact a mediator's hand gestures and eye contact may have on the parties participating in the mediation session. This awareness is crucial and beneficial in any mediation session as it is when the mediator is one from a majority culture and the parties are that of a minority culture. 
Hofstede's cultural dimensions may help one understand the roots of values within a culture as they are able to fluctuate from person to person, while other values are more grounded. Hofstede's dimensions could be understood as the 'framework' in understanding cultural values. That said, it was not until later that Schwartz (2006) developed his theory of culture based on individual differences in value priorities and their effects on belief and behavior systems. Schwartz's theory revolves around the idea that there are three cultural-value dimensions that all societies confront.

The dimensions are embeddedness versus autonomy, hierarchy versus egalitarianism, and mastery versus harmony. These three value dimensions derive their framework from seven cultural value orientations: embeddedness, intellectual autonomy, affective autonomy, egalitarianism, hierarchy, harmony, and mastery. Embeddedness versus autonomy describes the extent to which people are autonomous or embedded in their groups and is most similar to Hofstede's dimension of Individualism versus Collectivism. Two types of autonomy have been introduced to delve deeper into this dimension. The first is intellectual autonomy in which creativity is encouraged, whereas affective autonomy is described as the affective encouragement for pleasurable experiences. On the other hand, embeddedness describes an encouragement towards collectivity and the value of social relationships, such as traditions within that group (Schwartz, 2006).

The dimension of hierarchy versus egalitarianism is similar to that of Hofstede's power distance. Moreover, egalitarianism is defined as "perceiving others as moral equals" (Schwartz, 2006). Egalitarianism encourages values such as social justice and equality amongst those in the society. On the other end of the spectrum is the idea of a social hierarchy within the society. With this, the value of authority is encouraged and there is an unequal distribution of power within the society. The last of the dimensions is the idea of mastery versus harmony. In this, harmony refers to fitting oneself into the world and appreciating differences, whereas mastery is the idea of working towards mastering or changing the environment. In other words, the two are different in their reasoning for human purpose (Schwartz, 2006).

While Hofstede and Schwartz share similar concepts for their theories of cultural values, Schwartz's values are based more so on individual needs and purpose while Hofstede's values are looked at with respect to extrinsic values in a society (Schwartz, 1994). Moreover, Schwartz (1992) looks at values based on needs, which consist of individuals' requirements as biological organisms; society's necessity for structured and coordinated social interaction; and, lastly, the group's need for survival and support. On the other hand, Hofstede's value framework is related to macroeconomic variables, shaped based on norms (Hofstede, 2001).

In regard to the future of studies in cultural values, some critics suggest that the number of dimensions should be extended. Triandis (2004) has defended this position, and the GLOBE (Global Leadership and Organizational Behaviour Effectiveness) project tried to extend Hofstede's five dimensions to eighteen dimensions. GLOBE is a large-scale application that was conceived by United States management scholar Robert J. House in 1991 (Grove, 2005). Efforts to effectively increase the number of dimensions has not yet occurred; increasing the number of dimensions would only be meaningful when their concepts and statistics are independent of those already used and studied. 
To illustrate these concepts, I devised a research question revolving around surveys. The objective when gathering these surveys is to see how various cultures perceive nonverbal communication in its contribution to a mediation session. I specifically explore the following research question: To what extent can we predict the participants' preference for high nonverbal presentation in a mediation session? My study measures individuals' cultural values via the Personal Cultural Orientations Scale, representative of Hofstede's six cultural dimensions.

I further use two videos depicting a mediation session that include a Caucasian woman as the mediator to display nonverbals. One of these videos consists of the mediator displaying heavy eye contact and hand gestures, and one with limited-to-no eye contact, as well as no hand gestures. The video was evaluated by a faculty member in the Communication Studies department to ensure that the variation of high nonverbals and low nonverbals was adequately portrayed. Persons of different ethnicities, races, and nationalities have been asked a series of questions in accord with the Personal Cultural Orientations Scale. Participants then watched the two videos of the mediation session and followed with a brief four-question survey, the purpose being for them to reflect on the nonverbals they witnessed in the videos.

Questions include whether or not they enjoyed the mediators heavy display of nonverbals, whether or not they found the heavy display of nonverbals to be engaging, and if - were they a party in the mediation session - they would prefer the heavy use of nonverbals as opposed to the lack of nonverbals. The subjects of the data collection are those enrolled in an Introduction to Communication class as well as an Intercultural Communications class, with all being representatives of diverse groups.

Furthermore, it is important to recognize the difference of cultural values for a Caucasian woman who has behaviors featuring typical American stereotypes. Moreover, the mediator in the videos can be described as an individualist, informal, lowcontext communicator who uses a rationalbased approach to problem solving and conflict resolution. It is because of this "identity" that changing perspectives and adapting to other culture's values when mediating can be difficult. Moreover, lacking the ability to be what you are not and consequently not being able to relate to people from other cultures as they might prefer to be related can be detrimental. However, that is not to say that one cannot try and succeed.

As for protocol, the research hinged on a collection of 313 surveys. The online, 15-minute survey was sent out to those enrolled in an Introduction to Communication and Intercultural Communications courses at a large southwestern university. The online survey was created via Qualtrics.

Of the 313 participants, $176(56 \%)$ identify as female, $121(38 \%)$ identify as male, two $(.006 \%)$ identify as another gender, and 14 chose not to answer. As far as ethnicity, 143 (45\%) identify as White, 64 $(20 \%)$ identify as Black or African American, $75(23 \%)$ identify as Hispanic, Latino, or of Spanish origin, one $(.003 \%)$ identifies as American Indian or Alaskan Native, 20 (.06\%) identify as Asian, five (.01\%) identify as Middle Eastern or North African, zero identify as Native Hawaiian or Pacific Islander, and five $(.01 \%)$ identify as another ethnicity. In regard to nationality, $258(82 \%)$ are of American nationality, eight (.02\%) are of Asian nationality, eight $(.02 \%)$ are of 
European nationality, one $(.003 \%)$ is of Japanese nationality, $21(.06 \%)$ are of Mexican nationality, and twelve (.03\%) are of another nationality.

As for personal cultural orientation, researchers began using various self-report scales with the purpose of measuring individual cultural values as they correspond with Hofstede's national-based dimensions. These include the 32-item work-related values scale (Hofstede 1980), the 32-item Idiocentrism-Allocentrism Scale (Triandis et al., 1985), the 20-item Value Survey Module, VSM 94 (Hofstede 1994), the 24-item SelfConstrual Scale, SCS (Singelis 1994), the 26item Cultural Values Scale, CVSCALE (Yoo et al., 2011), and the 20-item cultural dimensions scale (Furrer, Liu, \& Sudharshan, 2000).

These scales face criticism for treating each cultural value as a unidimensional construct, despite evidence that values are interrelated (Bearden et al. 2006; Oyserman et al, 2002; Soares et al, 2007; Taras, Rowney, \& Steel, 2009). Due to the criticisms that these scales faced, the Personal Orientations Scale is used to measure cultural values on an individual level. Personal cultural orientations consist of shared cultural values and norms as well as personal beliefs based on unique individual experiences. Hence, there are theoretical reasons to expect a conceptual link between national level and individual level cultural values (Oyserman et al., 2002). This 40question scale is designed to effectively measure Hofstede's Cultural Dimensions on a personal level.

The dimensions are: Independence versus Interdependence, which is reflective of Hofstede's Individualism versus Collectivism dimension; Risk Aversion versus Ambiguity Intolerance, which is reflective of Hofstede's Uncertainty Avoidance dimension; Power versus Social Equality, which is reflective of Hofstede's Power Distance dimension; Masculinity versus Gender Equality, which is reflective of Hofstede's Masculine versus Feminine dimension; and Tradition versus Prudence, which is reflective of Hofstede's long-term versus short-term orientation dimension. Each dimension is broken down into four or five questions that are depictive of that cultural dimension. Those participating in the survey are to respond to the questions based on a seven-point scale of strongly agree to strongly disagree, with 7 being strongly agree and 1 being strongly disagree.

\section{Results}

The means and standard deviations of the personal cultural orientations appear in Table 2. We conducted a series of simple linear regressions to investigate the relationship between each of the personal cultural orientations' subscales (Independence, Interdependence, Risk Aversion, Power, Social Inequality, Ambiguity Intolerance, Masculinity, Gender Equality, Tradition, and Prudence) and preference for high nonverbal mediation contexts (see Table 3). Simple linear regression showed a significant relationship between Interdependence and participants' preference for high nonverbals in a mediation session $(\mathrm{F}(1,311)=3.74, p=.05)$, with an $R^{2}$ of .012 . For every one-unit increase in interdependence, participants preference for high nonverbal mediation session increased $0.16(t=1.93, p=.05)$.

\section{Table 2. Means and Standard Deviations of Personal Cultural Orientations}




\begin{tabular}{lcc}
\hline Personal Cultural Orientation & Mean & SD \\
\hline Independence & 5.95 & 0.64 \\
Interdependence & 5.90 & 0.77 \\
Risk Aversion & 4.18 & 1.16 \\
Power & 4.49 & 1.25 \\
Social Inequality & 3.18 & 1.18 \\
Ambiguity Intolerance & 5.21 & 1.18 \\
Masculinity & 4.39 & 1.09 \\
Gender Equality & 6.48 & 0.80 \\
Tradition & 5.62 & 1.14 \\
Prudence & 5.86 & 0.93 \\
\hline
\end{tabular}

Simple linear regression showed a significant relationship between Gender Equality and participants' preference for high nonverbals in a mediation session ( $\mathrm{F}(1,311)$ $=11.60, p=.00)$, with an $R^{2}$ of .04 . For every one-unit increase in gender equality, participants preference for high nonverbals in a mediation session increased $0.30(t=3.40$, $p=0.0)$.

Table 3. Linear Regression Analysis of Personal Cultural Orientations and Preference for High Nonverbal Mediation Contexts $(\mathbf{N}=\mathbf{3 1 2})$

\begin{tabular}{lcccc}
\hline \multicolumn{1}{c}{$\begin{array}{c}\text { Personal } \\
\begin{array}{c}\text { Cultural } \\
\text { Orientations }\end{array}\end{array}$} & $R^{2}$ & $\mathrm{~F}(1,311)$ & & $\mathrm{SE}$ \\
\hline Independence & 0.003 & 0.75 & -0.03 & 0.11 \\
Interdependence & 0.012 & $3.74^{*}$ & 0.15 & $0.08^{* *}$ \\
Risk Aversion & 0.000 & 0.09 & 0.02 & 0.06 \\
Power & 0.000 & 0.17 & 0.02 & 0.05 \\
Social Inequality & 0.001 & 0.33 & -0.03 & 0.06 \\
Ambiguity & 0.003 & 0.81 & 0.05 & 0.06 \\
Intolerance & & & &
\end{tabular}




$\begin{array}{lcccc}\text { Masculinity } & 0.000 & 0.17 & -0.03 & 0.06 \\ \text { Gender Equality } & 0.036 & 11.60^{* * *} & 0.30 & 0.09^{* * * *} \\ \text { Tradition } & 0.011 & 3.60 & 0.11 & 0.06 \\ \text { Prudence } & 0.002 & 0.52 & 0.05 & 0.07\end{array}$

${ }^{*} p<.05 ; * * t=1.93, p<.05 ; * * * p<.05 ; * * * * t=3.40, p<.05$

The simple linear regressions for Independence, $\mathrm{F}(1,311)=.10, p=.75$; Risk Aversion, $\mathrm{F}(1,311)=0.09, p=.76$; Power, $\mathrm{F}$ $(1,311)=0.14, p=.71$; Social Inequality, $\mathrm{F}$ $(1,311)=0.33$,

$p=.57 ;$ Ambiguity Intolerance, $\mathrm{F}(1,311)=$ $0.81, p=.37$; Masculinity, $\mathrm{F}(1,311)=0.17$, $p=.68$; Tradition, $\mathrm{F}(1,311)=3.60, p=.06$; Prudence, $\mathrm{F}(1,311)=0.53, p=.49$, and participants' preference for high nonverbal mediation sessions were not significant.

\section{Conclusion}

Mediation is a process in which individuals seek a settlement of their differences. It is important to acknowledge that the mediator's use of verbal and nonverbal communication carries significance in a mediation. It is part of the mediator's responsibility to help the parties feel comfortable relaying significant and personal information. For that reason, it is also important for the mediator to have awareness of the impact of their personal nonverbals and recognize the preferences of the parties for whom they are mediating to reach a successful outcome.

Nonverbal communication serves as an important role in communication and shows the evolution of humans from animals. Nonverbals also have the potential to communicate genuine thoughts and feelings significantly more than verbal communication. For this reason, it is important that the receiving party be aware of the cultural context in which the nonverbals are displayed. Understanding the roots of nonverbal communication across cultures is imperative to a respectful relationship and mediation session among those who have differing cultural values.

This study had individuals from varying cultures respond to questions after observing two videos of a mediator's opening statement. One video displayed high nonverbals (heavy eye contact and hand gestures) while the other showed a lack of eye contact and hand gestures. The individuals completing the survey were asked to rate their preference of the mediator's nonverbals from their individual cultural preferences. The data demonstrated the existence of two personal cultural orientations that showed a significant relationship between participants' responses and a preference for a heavy display of nonverbals in a mediation session. Moreover, as there was an increase in those who are more interdependent, there was a significant increase in preference for a heavy display of nonverbals in a mediation session. This significant relationship in preference for high nonverbals in a mediation session was also seen for the gender equality subscale.

The correlation - as shown through an increase in units for gender equality as participants' preference for high nonverbals in a mediation session increases - can be related to the idea that women and men share similar roles in society. Moreover, as they 
begin to occupy those equal roles, they may begin to share expressive traits (high nonverbals) as well. Participants' who agreed with the aspects of the gender equality personal cultural orientation subscale might agree that it is okay for men to be emotional sometimes (Sharma, 2009), displaying emotions through such nonverbals as hand gestures and facial expressions. To further draw on the correlation shown through an increase in units for gender equality as participants' preference for high nonverbals in a mediation session, increase can be related to Hofstede's $(1980,2001)$ feminine culture idea (reflective of gender equality subscale) that high displays of nonverbals are seen as cooperative and equalizing for cultural contexts in which most of the participants are familiar. This acceptance for a display in nonverbals for different genders may potentially be an explanation for the correlation in the participants' preference for high nonverbals in a mediation session.

The correlation shown through an increase in units for interdependence as participants' preference for high nonverbals in a mediation session increase did not come as a surprise. Moreover, Sharma (2009) and Hofstede (1980) suggests that those of a collectivistic culture (interdependent) use more high-context communication because they rely on nonverbal cues over verbal cues.

Since the data show a significant relationship between participants' personal cultural preferences and their preference for high nonverbals in a mediation session for two out of ten Personal Cultural Orientation subscales, it can be said that the Personal Cultural Orientations cannot significantly predict this specific group of participants' preferences for displays of nonverbals in a mediation session.

The importance of cultural
differences in perceptions of nonverbal

communication in mediation contexts is largely understudied. While this project was limited in its scope, the findings provide a direction for future research. Future possibilities for this study may include participants of different age groups, as a potential flaw in this study is that the group consists of college students who have been adapted to a certain display of nonverbals and therefore have created a bias. Future research could continue to explore the importance of gender equality and interdependence as it relates to perceptions of nonverbal communication behaviors in further depth. In particular, the gender of the mediator should be varied to see if that influences the participants' perceptions. A male mediator using highly expressive nonverbals may be perceived differently than a female mediator, as featured in the current study.

In recognition of the everchanging world in which we live and its impact on society, it is important to understand the value of this study in its contribution to increase awareness of the mediator's use of verbals and nonverbals in the mediation process.

\section{References}

Abramson, H. I. (2004). Mediation representation: Advocating in a problem-solving process. (pp. 242243). South Bend, Ind: National Institute for Trial Advocacy.

Andersen, P.A. (1997). Cues of Culture: The basis of intercultural differences in nonverbal communication. In Samovar, L.A., \& Porter. E. (Eds.), Intercultural Communication: $8^{\text {th }}$ edition. Belmont, CA: Wadsworth Publishing.

Archer, D. (1997). Unspoken diversity: Cultural differences in gestures. Qualitative Sociology, 20, 79-105. 
Retrieved

from

https://link.springer.com/content/pdf/

$10.1023 \% 2 F A \% 3 A 1024716331692$.

pdf

Argyle, M., \& Cook, M. (1976). Gaze and mutual gaze. New York: Cambridge University Press.

Barkai, J. (2008). What's a cross-cultural mediator to do? A low-context solution for a high-context problem. Cardozo Journal of Conflict Resolution, 10, (pp. 43-89). Retrieved from https://ssrn.com/abstract $=1434165$

Barna, L.M. (1997). Stumbling blocks in intercultural communication. In Samovar, L.A., \& Porter. E. (Eds.), Intercultural Communication: $8^{\text {th }}$ edition. Belmont, CA: Wadsworth Publishing.

Bearden, W. O., Money, R. B., \& Nevins, L., J. (2006). Multidimensional versus unidimensional measures in assessing national culture values: The Hofstede VSM 94 example. Journal of Business Research, 59, 195-203.

Beer, J., \& Packard, C. (2012). The Mediator's Handbook. British Columbia, Canada: New Society.

Clark, T. (1990). International marketing and national character: A review and proposal for an integrative theory. Journal of Marketing, 54(4): 66-79.

Darwin, C. (1998). The expression of emotion in man and animals. New York: Oxford University Press. (Original work published 1972)

Duncan, S. D. Jr. (1969). Nonverbal communication. Psychological Bulletin, 72, 118.
Ekman, P. (1972). Universal and cultural difference in the facial expression of emotion. In Cole, J. (Eds.), Nebraska symposium on motivation (pp. 207283). Lincoln, NE: University of Nebraska Press.

Ekman, P., \& Friesen, W. V. (1971). Constants across cultures in the face and emotion. Journal of Personality and Social Psychology, 17(2), 124129. Retrieved from https://doi.org/10.1037/h0030377

Ekman, P., \& Friesen, W. V. (1975). Unmasking the face: A guide to recognizing emotions from facial clues. Los-Altos, CA: Prentice-Hall.

Ekman, P., \& Oster, H. (1979). Facial expression of emotion. Annual Review of Psychology, 30, 527-554.

Fehr, B. J., \& Exline, R. V. (1987). Social visual interactions: a conceptual and literature review. In A. W. Siegman \& S. Feldstein (Eds.), Nonverbal Behavior and Communication (Vol. 2, pp. 225-326). Hillsdale, NJ: Erlbaum.

Furrer, O., Liu, B. S.-C., \& Sudharshan, D. (2000). The relationships between culture and service quality perceptions: Basis for cross-cultural market segmentation and resource allocation. Journal of Service Research, 2(4), 355-371. https://doi.org/10.1177/10946705002 4004

Goman, C. (2008). The nonverbal advantage. Berret - Koehler Publishers, Inc., San Francisco, p. 143.

Grove, N. C. (2005). Introduction to the GLOBE research project on leadership worldwide. Retrieved 
from

http://www.grovewell.com/pub-

GLOBE-intro.html

Hall, E. T. (1977). Beyond culture. Garden City, NY: Doubleday \& Company, Inc

Hofstede, G. (1980). Culture's consequences: International differences in workrelated values. Beverly Hills, CA: Sage.

Hofstede, G. \& Bond, M.H. (1988). The Confucius connection: From cultural roots to economic growth. Organizational Dynamics, 16(4), 4 21.

Hofstede, G., Arrindell, W. A., Best, D. L., de Mooij, M. Hoppe, M. H., van de Vliert, E., van Rossum, J. H. A., Verweij, J., Vunderink, M. \& Williams, J. E. (1998). Masculinity and femininity: The taboo dimension of national cultures. Thousand Oaks, CA: Sage.

Hofstede, G. (2001). Culture's consequences: comparing values, behaviors, institutions, and organizations across nations. Thousand Oaks, CA: Sage (co-published in the PRC as Vol. 10 in the Shanghai Foreign Language Education Press SFLEP Intercultural Communication Reference Series, 2008)

Hofstede, G. (2009). Dimensionalizing cultures: the Hofstede model in context. Online Readings in Psychology and Culture (Unit 17, Chapter 14). International Association for Cross-Cultural Psychology.

Hofstede, G. (2010). The GLOBE debate: Back to relevance. Journal of
International Business Studies, 41, 1339-46.

Hofstede, G. (2011). Dimensionalizing cultures: The Hofstede model in context. Online Readings in Psychology and Culture, 2(1). Retrieved from https://doi.org/10.9707/23070919.1014

Kluckhohn, C. (1962). Universal categories of culture. In S. Tax (Ed.), Anthropology today: Selections (pp. 304-20). Chicago, IL: University of Chicago Press (first published 1952).

Mandal, F. B. (2014). Nonverbal communication in humans. Journal of Human Behavior in the Social Environment, 24(4), 417-421. https://doi.org/10.1080/10911359.20 13.831288

Marsh, A. A., Elfenbein, H. A., \& Ambady, N. (2003). Nonverbal "accents": Cultural differences in facial expressions of emotion. Psychological Science (0956-7976), 14(4), 373-376. Retrieved from https://libproxy.library.unt.edu:9443/ loginurl=http://search.ebscohost.com $/$ login.aspx?direct $=$ true $\& \mathrm{db}=\mathrm{s} 3 \mathrm{~h} \& \mathrm{~A}$ $\mathrm{N}=10053672 \&$ scope $=$ site

Matsumoto, D. (2006). Culture and nonverbal behaviour. Retrieved from http://www.davidmatsumoto.com/co ntent/Matsumoto $\% 20$ Chapter $\% 2012$ $\% 20$ Pages $\% 20$ from $\% 20$ Manusov $\% 2$ 0II\%20Proff-14.pdf

Oyserman, D., Coon, H. M., \& Kemmelmeier, M. (2002). Rethinking individualism and collectivism: evaluation of theoretical assumptions and meta-analyses. Psychological Bulletin, 128(1), 3-72. 
Pedersen, P. (2006). Multicultural conflict resolution. In M. Deutsch, P. T. Coleman, \& E. C. Marcus (Eds.), The handbook of conflict resolution: Theory and practice (p. 649-670). Wiley Publishing.

Poyotos, F. (1977). Forms and functions of nonverbal communication in the novel: A new perspective of the author character-reader relationship. Semiotica, 21, 295-338.

Remland, M. (2017). Nonverbal communication in everyday life. Thousand Oaks, CA: SAGE Publications, Inc.

Schwartz, S. H. (1992). Universals in the content and structure of values: Theoretical advances and empirical tests in 20 countries. In Advances in Experimental Social Psychology, Vol. 25, (pp. 1-65): Academic Press.

Schwartz, S. H. (1994). Are there universal aspects in the structure and contents of human values? Journal of Social Issues, 50(4), 19-45.

Schwartz, S. H. (2006). A theory of cultural value orientations: Explication and applications. Comparative Sociology, 5(2), 137-182.

Sharma, P. (2009). Measuring personal cultural orientations: scale development and validation. Journal of Academic Marketing Science, 38, 787-806.

Singelis, T. M. (1994). The measurement of independent and interdependent selfconstruals. Personality and Social Psychology Bulletin, 20(5), 580-591. https://doi.org/10.1177/01461672942 05014
Soares, A. M., M. Farhangmehr, \& A. Shoham. (2007). Hofstede's dimensions of culture in international marketing studies. Journal of Business Research, 60(3), 277-284.

Taras, V., Rowney, J., \& Steel, P. (2009). Half a century of measuring culture: Review of approaches, challenges, and limitations based on the analysis of 121 instruments for quantifying culture. Journal of International Management, $\quad 15, \quad 357-373$. 10.1016/j.intman.2008.08.005.

Topan, F. (2011). Nonverbal communication: a cultural guide. Retrieved from https://pdfs.semanticscholar.org/cab1 /f1 a4030a61 cb08eedc79610e8dd5fe4 7ac10.pdf

Triandis, H. C. (2004). The many dimensions of culture. Academy of Management Executive, 18, 88-93.

Weiner, M., Devoe, S., Rubinow, S., \& Geller, J. (1972). Nonverbal behaviour and nonverbal communication. Psychological Review, 79, 185-214.

Yoo, B., Donthu, N., \& Lenartowicz, T. (2011). Measuring Hofstede's five dimensions of cultural values at the individual level: development and validation of CVSCALE. Journal of International Consumer Marketing, 23 (3-4), 193-210. doi: 10.1080/08961530.2011.578059 